This is a peer-reviewed article published in 2011 in volume 3, number 2, pages 153-160, of the journal "Current Development in Oceanography". However, for unknown reasons, in 2019 the publisher (Pushpa Publishing House, Allahabad, India) entirely deleted this journal and all of its articles from its website (www.pphmj.com). During its existence, this journal was published only online. Therefore, to make the attached article permanently available to the scientific community, it is hereby submitted to MarXiv. 


\title{
SUBARCTIC SHORES WITHOUT AN ICE FOOT: LOW EXTREMES IN INTERTIDAL TEMPERATURE DURING WINTER
}

\author{
Ricardo A. Scrosati \\ Department of Biology \\ Saint Francis Xavier University \\ Antigonish, Nova Scotia B2G \\ 2W5, Canada \\ e-mail: rscrosat@stfx.ca
}

\begin{abstract}
On marine shores that freeze in winter, the intertidal zone becomes covered by an ice foot. Stable ice foots insulate intertidal organisms against highly negative air temperatures. On subpolar intertidal habitats that do not freeze, the periodic inundation with seawater at temperatures near its freezing point also prevents benthic organisms from experiencing highly negative temperatures. However, low tides do expose ice-free intertidal habitats to aerial conditions, but information on how negative temperature gets there during the winter is lacking. Using data loggers, this study measured the daily lowest temperature in rocky intertidal habitats on the Atlantic coast of Nova Scotia, Canada (which does not freeze), during the winter. As a control, temperature was also monitored above the intertidal zone (on tree branches). Intertidal temperature was almost as low as supratidal temperature, as the seasonal averages of daily minimum temperature were $-4.2^{\circ} \mathrm{C}$ and $-6.4^{\circ} \mathrm{C}$ (with absolute minima of $-14.1^{\circ} \mathrm{C}$ and
\end{abstract}

(C) 2011 Pushpa Publishing House

Keywords and phrases: ice foot, intertidal, sea ice.

Communicated by Hyo Choi

Received September 23, 2011; Revised November 2, 2011 
$-19.1^{\circ} \mathrm{C}$ ), respectively. The study site on the Atlantic coast is climatically similar to a site surveyed on the Gulf of St. Lawrence coast of Nova Scotia. However, the Gulf of St. Lawrence coast, which freezes in winter, showed milder intertidal temperatures, with a winter average of daily minimum temperature of $-1.9^{\circ} \mathrm{C}$ and an absolute minimum of only $-6.8^{\circ} \mathrm{C}$. Therefore, despite tidal influences, the absence of an ice foot exposes subpolar intertidal habitats to highly negative air temperatures.

\section{Introduction}

Thermal stress is a major factor affecting species performance in intertidal habitats, where extreme temperatures are often reached because of aerial exposure during low tides [21]. On subpolar shores, climatic conditions often include highly negative air temperatures in winter. However, the intertidal zone of many subpolar shores freezes during the winter, developing a thick ice foot if freezing lasts long enough [3]. A stable ice foot during the winter insulates the intertidal zone against extreme cold stress [24]. However, the extent to which the ice foot prevents very low temperatures from occurring in intertidal habitats, compared with daily immersions in seawater because of tides under similarly cold climates, has not been determined. An ideal method to investigate this issue would experimentally remove the ice foot during the winter and then monitor intertidal temperature dynamics. However, that approach is highly impractical, especially where ice is thick. The next best method would be to monitor intertidal temperature dynamics on shores that are subjected to a similar climate but that do not develop an ice foot.

The NW Atlantic coast exhibits a subarctic intertidal biota [1, 19]. In Nova Scotia (Canada), the Gulf of St. Lawrence coast freezes extensively in winter [23], covering the intertidal zone with a stable ice foot for several weeks (see a picture in [24]). At similar latitudes on the Atlantic coast of mainland Nova Scotia (distant only $100 \mathrm{~km}$ from the Gulf of St. Lawrence coast; Figure 1), the sea surface does not freeze [7], but climatic conditions are similar, including equally cold winters [14]. Thus, the present study 
Subarctic Shores Without an Ice Foot: Low Extremes in Intertidal ... 155

monitored intertidal temperature dynamics during winter on the Atlantic coast of Nova Scotia, establishing comparisons with previously published values for ice-covered intertidal habitats on the Gulf of St. Lawrence coast [24]. It was hypothesized that intertidal temperature would reach lower values on the ice-free Atlantic coast than on the frozen Gulf of St. Lawrence coast during winter.

\section{Materials and Methods}

Field measurements were done in Tor Bay Provincial Park $\left(45^{\circ} 11^{\prime} \mathrm{N}\right.$, $61^{\circ} 21^{\prime} \mathrm{W}$; Figure 1). Extensive intertidal areas, mainly composed of metamorphose sedimentary bedrock, occur on this coast. In late November 2007, 3 submersible temperature loggers (StowAway TidbiTs, Onset Computer, Bourne, MA, USA) were deployed on relatively smooth rocky surfaces (that is, not within crevices or other rare microhabitats) at the midintertidal zone (the full intertidal range being $1.8 \mathrm{~m}$ ) in wave-sheltered habitats. The loggers were secured with plastic cable ties to metallic hooks affixed with marine epoxy (A-788 Splash Zone Compound, Z-Spar, Los Angeles, CA, USA) to the substrate in a way that loggers made almost no contact with the rocky substrate. To record temperature dynamics solely in aerial conditions (supratidal), 2 loggers were affixed to branches ( $2 \mathrm{~m}$ above the ground) of spruce trees that faced the sea directly. In early April 2008, all of the loggers were collected. Apparently due to wave action, 2 intertidal loggers were damaged, making their data impossible to read. Since temperature dynamics were very similar in the 2 supratidal loggers (data for only one is presented here for simplicity), the data from the intact intertidal logger are likely representative of intertidal temperature dynamics.

\section{Results}

Between 1 December 2007 and 4 April 2008, the daily minimum temperature at the intertidal zone was often negative (Figure 2(a)). The coldest period occurred during the second half of January, when intertidal temperature reached its lowest value for the season $\left(-14.1^{\circ} \mathrm{C}\right)$. In fact, the 4 
lowest daily values for the intertidal zone occurred during that period (Figure 2(a)). The supratidal habitat experienced a similar amount of days with negative values of daily minimum temperature (Figure 2(b)). The coldest period for the supratidal habitat also occurred during the second half of January, with a lowest value of $-19.1^{\circ} \mathrm{C}$.

Overall, there was a high correspondence in the daily temperature minima throughout time between the intertidal and supratidal zones ( $r=0.88, \quad P<0.001, \quad n=126)$. The seasonal average of daily minimum temperature was similar at the intertidal $\left(-4.2 \pm 0.3^{\circ} \mathrm{C}\right.$, mean $\left.\pm \mathrm{SE}, n=126\right)$ and supratidal $\left(-6.4 \pm 0.4^{\circ} \mathrm{C}\right)$ habitats. At the intertidal zone, 11 days experienced temperatures lower than $-10^{\circ} \mathrm{C}$ and 50 days lower than $-5^{\circ} \mathrm{C}$ (Figure 2(a)).

\section{Discussion}

Previous measurements taken in supratidal habitats on the Gulf of St. Lawrence coast, about $100 \mathrm{~km}$ away from the Atlantic coast study site, indicate that the winter temperature regime is similar on both coasts, as the former experienced a lowest value of daily minimum temperature of $-19.8^{\circ} \mathrm{C}$ and a seasonal average of daily minimum temperature of $-7.2^{\circ} \mathrm{C}$ [24]. Thus, as indicated previously by climatic information [14], the in-situ data for supratidal habitats from the two coasts support the valid use of both shores to test the hypothesis of the present study. Under this view, the intertidal data obtained for both shores support the hypothesis. This is so because, at the intertidal zone on the Gulf of St. Lawrence coast, which is covered by a thick ice foot during the winter, the winter average of daily minimum temperature was $-1.9^{\circ} \mathrm{C}$ and the absolute minimum was only $-6.8^{\circ} \mathrm{C}$ [24]. In other words, given the same basic climatic conditions, intertidal habitats without a stable

ice foot experience lower temperatures in winter (comparable to those occurring on land) than intertidal habitats on ice-covered shores.

The biological implications of these findings are important. Intertidal macroalgae and invertebrates from cold-temperate (subpolar) shores are 
Subarctic Shores Without an Ice Foot: Low Extremes in Intertidal ... 157

physiologically adapted to surviving subzero temperatures [8, 26, 27]. However, mortality occurs when certain extremes are surpassed. For example, winter lethal temperatures range between $-10^{\circ} \mathrm{C}$ and $-14^{\circ} \mathrm{C}$ for many of these organisms [2, 5, 8, 10-12, 18, 28]. Although body temperature may not always correlate highly with air temperature $[15,16]$, this study has revealed that winter intertidal temperature frequently reaches lower values than lethal temperatures. Even when body temperature may not drop below lethal temperatures, survivorship may be compromised, because the repeated exposure to sublethal (but still negative) temperatures can also cause high mortality [5, 13, 20, 22]. Thus, the data of this study suggest that extreme cold stress [6] might constitute a significant mortality factor on shores that do not develop an ice foot. Because of the thermal insulation provided by the ice foot, winter mortality on ice-covered shores would result mainly from other factors such as the scouring exerted by moving ice because of tides, waves, wind and currents $[4,17,25]$. As climate change gradually suppresses the winter formation of intertidal ice on many subpolar shores, physiological stress may become more important than physical stress in determining intertidal community dynamics.

\section{Acknowledgements}

I am grateful to Cortney A. Watt, for her field assistance. Research is funded by grants awarded to the author by the Canada Research Chairs (CRC) program, the Canada Foundation for Innovation (CFI), and the Natural Sciences and Engineering Research Council (NSERC; Discovery grant).

\section{References}

[1] W. H. Adey and L. C. Hayek, The biogeographic structure of the western North Atlantic rocky intertidal, Cryptogamie, Algol. 26 (2005), 35-66.

[2] A. Ansart and P. Vernon, Cold hardiness in molluscs, Acta Oecol. 24 (2003), 95-102.

[3] D. K. A. Barnes, The influence of ice on polar nearshore benthos, J. Mar. Biol. Assoc. U. K. 79 (1999), 401-407. 
[4] P. Bergeron and E. Bourget, Shore topography and spatial partitioning of crevice refuges by sessile epibenthos in an ice-disturbed environment, Mar. Ecol. Prog. Ser. 28 (1986), 129-145.

[5] E. Bourget, Seasonal variations of cold tolerance in intertidal molluscs and relation to environmental conditions in the St. Lawrence Estuary, Can. J. Zool. 61 (1983), 1193-1201.

[6] C. E. Braby, Cold stress, M. W. Denny and S. D. Gaines, eds., Encyclopedia of Tidepools and Rocky Shores, University of California Press, Berkeley, 2007, pp. 148-150.

[7] Canadian Ice Service, 2011, http://ice-glaces.ec.gc.ca

[8] J. Collén and I. R. Davison, Reactive oxygen production and damage in intertidal Fucus spp. (Phaeophyceae), J. Phycol. 35 (1999), 54-61.

[9] J. Collén and I. R. Davison, Seasonality and thermal acclimation of reactive oxygen metabolism in Fucus vesiculosus (Phaeophyceae), J. Phycol. 37 (2001), 474-481.

[10] P. A. Cook and P. A. Gabbott, Seasonal changes in the free glycerol level in the body parts of the adult barnacle Balanus balanoides, Mar. Biol. 7 (1970), 11-13.

[11] D. J. Crisp and D. A. Ritz, Changes in temperature tolerance of Balanus balanoides during its life cycle, Helgol. Meeresunters. 15 (1967), 98-115.

[12] I. R. Davison, S. R. Dudgeon and H. M. Ruan, Effect of freezing on seaweed photosynthesis, Mar. Ecol. Prog. Ser. 58 (1989), 123-131.

[13] S. R. Dudgeon, I. R. Davison and R. L. Vadas, Freezing tolerance in the intertidal red algae Chondrus crispus and Mastocarpus stellatus: relative importance of acclimation and adaptation, Mar. Biol. 106 (1990), 427-436.

[14] Environment Canada, 2011, http://climate.weatheroffice.gc.ca

[15] B. Helmuth, How do we measure the environment? Linking intertidal thermal physiology and ecology through biophysics, Integ. Comp. Biol. 42 (2002), 837-845.

[16] B. Helmuth, B. R. Broitman, L. Yamane, S. E. Gilman, K. Mach, K. A. S. Mislan and M. W. Denny, Organismal climatology: analyzing environmental variability at scales relevant to physiological stress, J. Exp. Biol. 213 (2010), 995-1003.

[17] L. E. Johnson, Ice scour, M. W. Denny and S. D. Gaines, eds., Encyclopedia of Tidepools and Rocky Shores, University of California Press, Berkeley, 2007, pp. 289-291. 
Subarctic Shores Without an Ice Foot: Low Extremes in Intertidal ... 159

[18] S. H. Loomis, Freezing tolerance of marine invertebrates, Oceanogr. Mar. Biol. 33 (1995), 337-350.

[19] A. C. Mathieson, C. A. Penniman and L. G. Harris, Northwest Atlantic rocky shore ecology, A. C. Mathieson and P. H. Nienhuis, eds., Ecosystems of the World., Vol. 24., Intertidal and Littoral Ecosystems, Elsevier, Amsterdam, 1991, pp. 109-191.

[20] D. J. Murphy and L. C. Johnson, Physical and temporal factors influencing the freezing tolerance of the marine snail Littorina littorea (L.), Biol. Bull. 158 (1980), 220-232.

[21] D. Raffaelli and S. Hawkins, Intertidal Ecology, Chapman \& Hall, London, 1996.

[22] W. Roland and R. A. Ring, Cold, freezing, and desiccation tolerance of the limpet Acmaea digitalis (Eschscholtz), Cryobiology 14 (1977), 228-235.

[23] F. J. Saucier, F. Roy, D. Gilbert, P. Pellerin and H. Ritchie, Modeling the formation and circulation processes of water masses and sea ice in the Gulf of St. Lawrence, Canada. J. Geophys. Res. 108, C8 (2003), 3269.

[24] R. Scrosati and L. K. Eckersley, Thermal insulation of the intertidal zone by the ice foot, J. Sea Res. 58 (2007), 331-334.

[25] R. Scrosati and C. Heaven, Field technique to quantify intensity of scouring by sea ice in rocky intertidal habitats, Mar. Ecol. Prog. Ser. 320 (2006), 293-295.

[26] K. B. Storey and J. M. Storey, Natural freezing survival in animals, Annu. Rev. Ecol. Syst. 27 (1996), 365-386.

[27] C. L. Waller, M. R. Worland, P. Convey and D. K. A. Barnes, Ecophysiological strategies of Antarctic intertidal invertebrates faced with freezing stress, Polar Biol. 29 (2006), 1077-1083.

[28] R. J. Williams, Freezing tolerance in Mytilus edulis, Comp. Biochem. Physiol. 35 (1970), 145-161. 


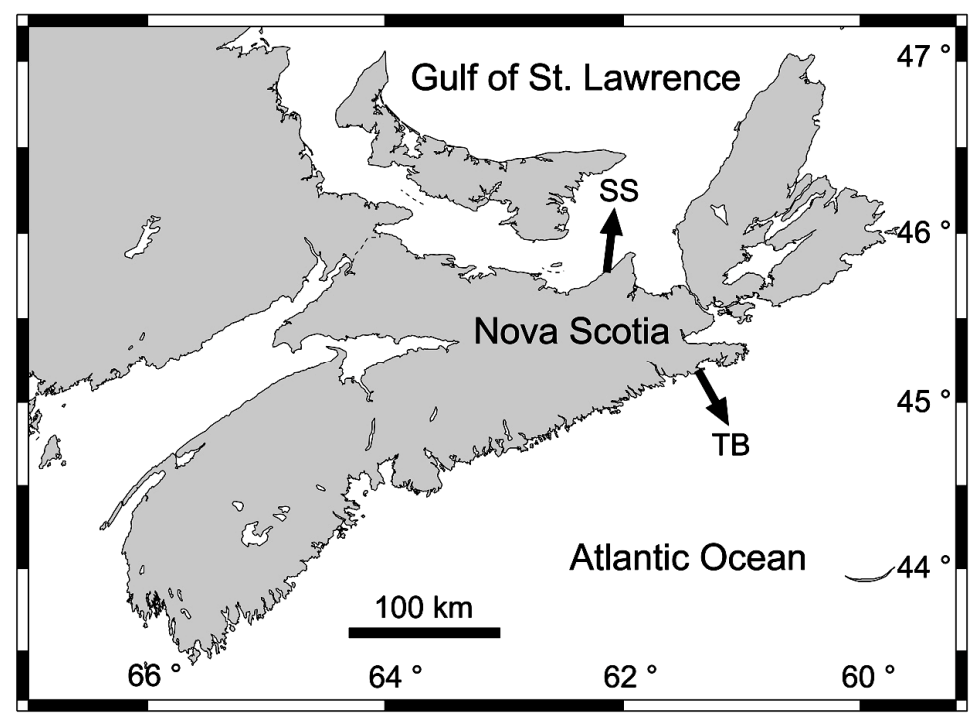

Figure 1. Map showing the location of Tor Bay Provincial Park (TB), on the Atlantic coast of Nova Scotia, and a previously studied site (Sea Spray Shore, SS) on the Gulf of St. Lawrence coast of Nova Scotia.
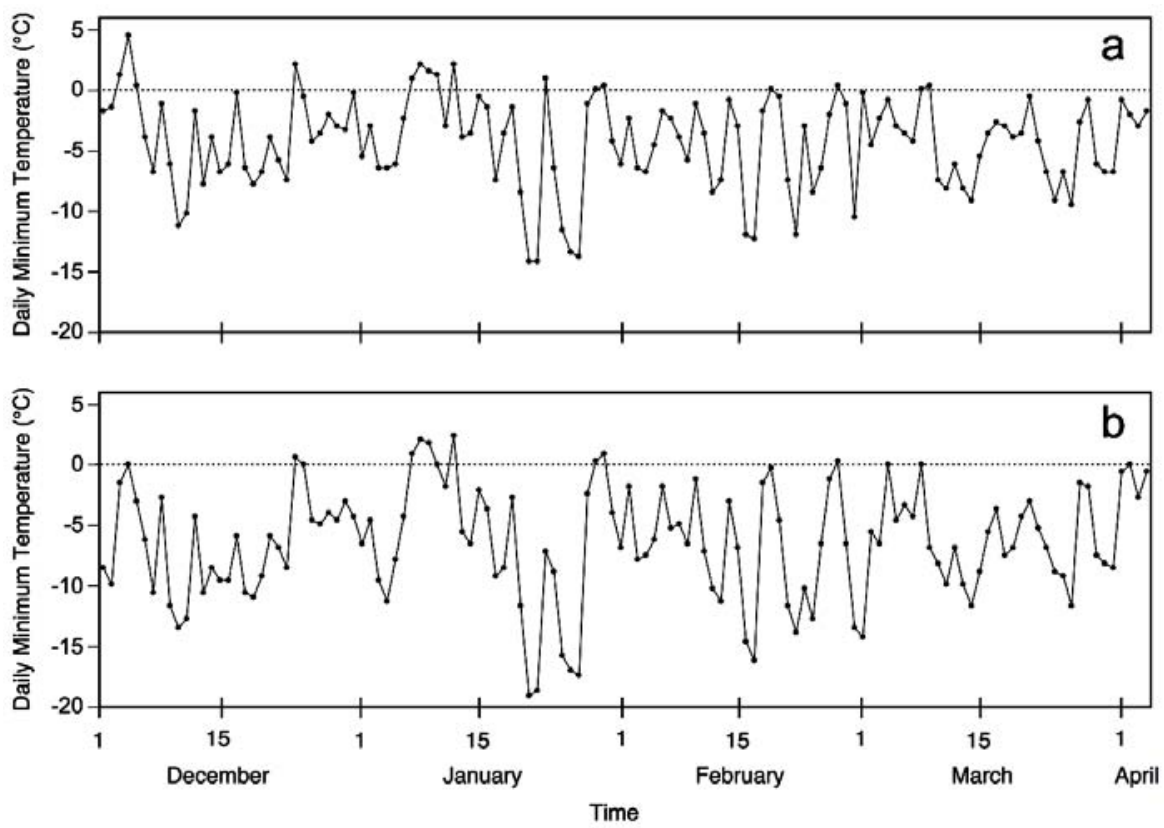

Figure 2. Daily minimum temperature $\left({ }^{\circ} \mathrm{C}\right)$ between 1 December 2007 and 4 April 2008 at (a) the intertidal zone and (b) the supratidal zone of Tor Bay Provincial Park, on the Atlantic coast of Nova Scotia. 